\title{
P118: Implementation of the World Health Organization multimodal hand hygiene improvement strategy in a pediatric Brazilian hospital
}

\author{
AM Ribeiro ${ }^{*}$, Francisca Luzilene N Della Guardia, Fernanda Calixto Martins, Virginia Maria Ramos Sampaio
}

From 2nd International Conference on Prevention and Infection Control (ICPIC 2013)

Geneva, Switzerland. 25-28 June 2013

\section{Introduction}

Hand hygiene is the cornerstone measure to prevent healthcare associated infection (HAI) and to ensure safe patient care. To improve compliance to hand hygiene $(\mathrm{HH})$ and, decrease HAI, the Hospital Infantil Albert Sabin (HIAS) implemented the World Health Organization (WHO) Multimodal Hand Hygiene Improvement Strategy.

\section{Objectives}

Assess the effectiveness of this strategy in terms of adherence to hand hygiene practice in a Pediatric hospital in Brazil's northeast.

\section{Methods}

The project was supported by the Brazilian government which formally signed an agreement in November 2007 to participate in the World Alliance for Patient Safety. The HIAS was selected by the National Health Surveillance Agency (ANVISA) Sentinel Network. The methodology followed the recommendations of the $\mathrm{WHO}$ and the original design was applied in three intensive care units (ICU) with 32 beds and 240 health workers in the period from 2008 to 2009. Compliance to hand hygiene was monitored by direct observation before and after intervention in the five moments indicated. The program Epi Info 6 was used to analyze data.

\section{Results}

The rate of adherence to hand hygiene was $42 \%$ before intervention and $57.8 \%$ after intervention, an increase of
$32 \%(\mathrm{p}<0.001)$. The nursing technicians showed the lower adherence rate to $\mathrm{HH}$ before the intervention (35.5\%), that increased to $56.1 \%$ after the intervention ( $\mathrm{p}$ 0.001). Adherence to $\mathrm{HH}$ "before touching the patient" rate was $38.9 \%$ before and $59.7 \%$ after intervention ( $\mathrm{p}<$ 0.001 ). There was an increased use of alcohol gel from $8 \%$ to $62 \%$ in the actions of $\mathrm{HH}$.

\section{Conclusion}

It was found an increase in hand hygiene adherence by health workers in all three ICU during the implantation of the WHO multimodal strategy. This strategy will be implemented in all areas of the hospital care.

\section{Disclosure of interest}

None declared.

Published: 20 June 2013

\section{doi:10.1186/2047-2994-2-S1-P118}

Cite this article as: Ribeiro et al:: P118: Implementation of the World Health Organization multimodal hand hygiene improvement strategy in a pediatric Brazilian hospital. Antimicrobial Resistance and Infection Control 2013 2(Suppl 1):P118.

Control Infection, Hospital Infantil Albert Sabin, Fortaleza, Brazil

(c) 2013 Ribeiro et al; licensee BioMed Central Ltd. This is an Open Access article distributed under the terms of the Creative Commons 